\title{
Formação de professores e Análise do Comportamento: Caracterização de Necessidades Formativas para a Docência em Matemática na Educação Básica
}

\author{
Jair Lopes Junior ${ }^{1}$ \\ Departamento de Psicologia da Universidade Estadual Paulista Júlio de Mesquita Filho, \\ Bauru, SP, Brasil \\ Deise Aparecida Peralta \\ Departamento de Matemática da Universidade Estadual Paulista Júlio de Mesquita Filho, \\ Ilha Solteira, SP, Brasil
}

\section{Resumo}

No Estado de São Paulo, a implantação do Currículo de Matemática para a Educação Básica e das Matrizes Curriculares de Referência para o Sistema de Avaliação do Rendimento Escolar determinou a prioridade de práticas de ensino diretamente voltadas para o desenvolvimento de competências e de habilidades. O objetivo deste artigo foi expor e discutir possíveis efeitos da implantação sobre a atuação profissional de professores que ensinam Matemática, bem como apresentar proposta de programas de investigação e de intervenção sobre os efeitos da mesma. A partir de análises documentais, verificou-se que um denso e variado conjunto de ações que definiu a implantação da atual política pública de avaliação de desempenho escolar prescindiu da investigação do impacto das medidas sobre os repertórios comportamentais predominantes dos professores responsáveis pela efetivação das mesmas. Foi caracterizada a necessidade formativa dos professores de derivar ou de transformar as diretrizes, as informações e as atividades propostas em classes de comportamentos ou de relações entre eventos (ações dos alunos e fatores do contexto diante dos quais tais ações são importantes) esperadas como resultado da exposição dos alunos às práticas de ensino. Respaldado em literatura recente da Análise do Comportamento que descreve procedimentos metodológicos para efetuar tal derivação no contexto das Diretrizes Curriculares Nacionais da Psicologia para demarcação da atuação do futuro psicólogo, há a proposição da extensão de tais procedimentos em investigações e intervenções colaborativas com professores como estratégia de desenvolvimento das aprendizagens profissionais correspondentes com as necessidades formativas assinaladas.

Palavras-chave: Docência em Matemática, formação de professores, Análise do Comportamento.

\section{Teacher Education and Behavior Analysis: Characterization of Formative Needs in Teaching Mathematics at Basic Education Level}

\begin{abstract}
In São Paulo, the implementation of the Mathematics Curriculum for Basic Education and Reference System for the Evaluation of Educational Achievement has determined the priority of teaching practices

Endereço para correspondência: Departamento de Psicologia, Universidade Estadual Paulista "Júlio de Mesquita Filho", Faculdade de Ciências, Campus de Bauru, Av. Eng. Luiz Edmundo Carrijo Coube, 14-01, Bauru, SP, Brasil 17047-625. Fone: (14) 31036087; Fax (14) 31036087. E-mail: jlopesjr@fc.unesp.br
\end{abstract}


directly related to the development of skills and abilities. The aim of this paper was to present and discuss possible effects of deployment on the professional performance of teachers who teach mathematics and to present proposed research and intervention programs on the effects of it. From documentary analyzes, we found that a dense and varied set of actions that define the implementation of current public policy evaluation of school performance waived the investigation of the impact of measures on the prevailing behavioral repertoires of teachers responsible for effecting the same. It characterized the need to derive training of teachers or change the guidelines, information and activities proposed to conduct classes or relationships between events (actions of the students of the context and factors before whom such actions are important) expected as a result of exposure of students to teaching practices. Supported in recent literature of behavior analysis that describes the methodological procedures for making such derivation in the context of the National Curriculum Guidelines for demarcation of the Psychology about the future performance psychologist, is proposing the extension of such procedures in collaborative research and interventions with teachers as a strategy for learning development professionals with corresponding training needs indicated.

Keywords: Teaching in Mathematics, teacher education, Analysis of Behavior.

\section{La Formación del Profesorado y el Análisis de la Conducta: Caracterización de las Necesidades de Capacitación en la Enseñanza de Matemáticas a Nivel de Educación Básica}

\section{Resumen}

En São Paulo, la implementación del currículo de matemáticas para la Educación Básica y la Matriz de Referencia Curricular para Evaluación de Rendimiento Escolar ha determinado la prioridad de enseñar destrezas y habilidades. El objetivo de este trabajo fue presentar y discutir los posibles efectos de la implementación en el desempeño profesional de los maestros que enseñan las matemáticas y de presentar propuestas de programas de investigación e intervención sobre los efectos de la misma. Los exámenes documentales testificaron que la aplicación de la evaluación del rendimiento escolar prescindió de la investigación del impacto de las medidas en los comportamientos de los profesores encargados de efectuar la misma. Se caracterizó las necesidades de formación de los profesores para derivar o transformar las directrices, información y actividades propuestas en los comportamientos o en las relaciones entre clases de eventos que se esperan como resultado de la exposición de los alumnos a las prácticas de enseñanza. Compatible con la literatura reciente de Análisis de la Conducta que describe los procedimientos metodológicos para realizar la derivación en el contexto de las Directrices Curriculares Nacionales, se propone la ampliación de tales procedimientos en la investigación colaborativa y las intervenciones con los profesores como una estrategia de desarrollo de los aprendizajes correspondientes a las necessidades de formación que se indican.

Palabras clave: Docencia en Matemáticas, la formación del profesorado, análisis de comportamiento.

A investigação experimental sobre processos comportamentais e cognitivos demarca incontestes contribuições da Psicologia para a compreensão de dimensões relevantes no ensinar e no aprender repertórios e conteúdos de distintas áreas curriculares e, em particular, a Matemática. Seguramente, e em consonância com publicações recentes em língua portuguesa (Carmo \& Prado, 2010; Henklain \& Carmo, 2013; Hübner \& Marinotti, 2004), o presente número da revista Temas em Psicologia documenta e garante visibilidade para parcela expressiva da produção de conhecimentos sobre os processos acima aludidos. 
Partindo do franco reconhecimento das contribuições derivadas da investigação experimental, o presente artigo objetiva expor e discutir outra modalidade de produção de conhecimento que poderia igualmente fortalecer e consolidar contribuições da Psicologia para o ensino e a aprendizagem em contextos curriculares na Educação Básica obrigatória, concentrando-se ênfase no componente curricular de Matemática.

Nas últimas décadas, de modo reincidente, verificou-se a edição de políticas públicas diretamente comprometidas com a melhora do desempenho escolar de alunos nos diferentes ciclos da Educação Básica obrigatória. Como dimensões relevantes e definidoras de tais políticas, cumpre destacar considerável acervo de material bibliográfico, bem como a implantação de sistemas de avaliação de rendimento escolar em larga escala (Secretaria da Educação do Estado de São Paulo [SEE/SP], 2008a, 2008b, 2009, 2010). Em seu conjunto, estima-se que a implantação e a disseminação das dimensões que definem as políticas públicas colocaram os professores dos diferentes ciclos da Educação Básica diante de diretrizes, de orientações, de matrizes, de metas, enfim, diante da necessidade de reavaliação, de readequação e de novas aprendizagens de práticas e de estratégias que definem a profissão docente.

Este artigo expõe inicialmente ocorrências relevantes para a compreensão da implantação do Sistema de Avaliação em Larga Escala do Estado de São Paulo (SARESP) com foco na área curricular da Matemática. Advoga-se que, como medida de impacto ou mesmo como fator decorrente de tal implantação, insuficiências foram registradas para o desenvolvimento de repertórios profissionais dos professores que, em última análise, seriam os principais agentes responsáveis pela obtenção dos índices e dos resultados previstos em termos governamentais.

Fundamentado em uma proposta de caracterização das insuficiências em termos do atendimento das necessidades formativas correspondentes com a implantação do SARESP, o presente artigo também expõe o delineamento de estratégias de investigação em ambiente escolar e com envolvimento direto do professor que poderiam concretizar a produção de conhecimentos de modo a fortalecer e a ampliar as contribuições da Análise do Comportamento para a compreensão do desenvolvimento de repertórios de ensino na formação profissional do docente que ministra conteúdos curriculares de Matemática na Educação Básica.

\section{O Sistema de Avaliação de Desempenho Escolar e as Necessidades Formativas}

O SARESP constitui-se em um amplo programa de avaliação externa, com aplicação anual, implantado em 1996 pela SEE/SP para os anos intermediários e finais dos Ciclos I e II do Ensino Fundamental e o terceiro ano do Ensino Médio. De particular relevância para o presente artigo, apresentam-se as edições de 2007 e de 2008 , visto que ambas se constituíram em base das ações atuais de gestão da SEE/SP (2008a, 2009, 2010).

A partir do ano letivo de 2008 foi implantado, na rede estadual de ensino de São Paulo, um novo currículo. O Currículo, intitulado inicialmente Proposta Curricular do Estado de São Paulo, e, desde o ano de 2010, como Currículo do Estado de São Paulo, divide o ensino em quatro áreas do conhecimento: Ciências Humanas e suas Tecnologias; Ciências da Natureza e suas Tecnologias; Linguagens, Códigos e suas Tecnologias; e Matemática e suas Tecnologias. Para cada área, disciplina ou componente curricular foi elaborado e distribuído a todo professor, segundo informações do site da SEE/SP (www. rededosaber.sp.gov.br), o documento base Proposta Curricular, que apresenta os princípios e finalidades do novo currículo, como também as orientações gerais para sua implementação e aplicação.

Na Proposta Curricular de 2008, a Matemática se mantém em uma área específica sob três justificativas (SEE/SP, 2008b, 2008c). Primeiro, o fato de que uma parte da especificidade da Matemática resulta esmaecida quando ela é agregada ao grupo das linguagens em sentido amplo ou ao grupo das ciências. A Matemática compõe com a língua materna um par fundamental, mas de caráter complementar, sendo 
impossível reduzir um dos sistemas simbólicos ao outro. Em segundo lugar, a incorporação da Matemática à área de Ciências pode distorcer o fato de que a Matemática, mesmo oferecendo uma linguagem especialmente importante e adequada para a expressão cientifica, constitui um conhecimento especifico da Educação Básica. A inclusão da Matemática na área de Ciências teve o efeito salutar, no caso dos Parâmetros Curriculares Nacionais (PCN), de minimizar o risco de que o conteúdo matemático fosse concebido como um fim em si mesmo, enfatizando sua condição instrumental. Entretanto, a partir do conceito de competências, apresentado pelo Exame Nacional do Ensino Médio (ENEM), tal risco, segundo os autores do texto do Currículo, deixou de existir, e explicita-se que todos os conteúdos disciplinares, nas diversas áreas, são meios para a formação dos alunos como cidadãos e como pessoas. As disciplinas são imprescindíveis e fundamentais, mas o foco permanente da ação educacional deve situar-se no desenvolvimento das competências pessoais dos alunos. E por fim, o tratamento da Matemática como área específica talvez possa facilitar a incorporação critica dos inúmeros recursos tecnológicos de que dispomos para a representação de dados e o tratamento das informações, na busca da transformação de informação em conhecimento.

O "novo" Currículo, em vigor desde 2008, inicialmente como Proposta Curricular do Estado de São Paulo: Matemática - Ensino Fundamental: Ciclo II e Ensino Médio, trouxe consigo algumas ações de implantação.

A primeira ação de implementação foi lançar um projeto interdisciplinar, conhecido na rede de ensino estadual como Recuperação Intensiva, desenvolvido nos primeiros 42 dias letivos do ano de 2008, e cujo objetivo era concretizar e retomar as aprendizagens necessárias para a implantação da nova Proposta Curricular.

Outra finalidade desse projeto, segundo informações do site da SEE/SP, foi apresentar orientações didáticas para sala de aula, que produzissem um "movimento de ação - reflexão - ação" e que indicasse a consolidação das habilidades de leitura e produção de textos e as habilidades matemáticas - identificadas como deficientes de acordo com os resultados de exames de SARESP anteriores. Como materiais de apoio foram publicados e distribuídos a Revista do Professor e o Jornal do Aluno, que serviram como referência para essas "novas práticas" e para o planejamento do ano letivo, sendo que para apresentação desse projeto foram realizadas as "Videoconferências de Capacitação" (SEE/ SP, 2008b).

Com o propósito precípuo de capacitar o corpo docente para o citado projeto, cada diretor indicou quatro professores: dois que ensinavam Matemática (um no Ensino Fundamental e o outro no Ensino Médio) e dois que lecionavam Língua Portuguesa (idem), que receberam orientações que deveriam ser reproduzidas aos seus pares em suas escolas. O período de recuperação intensiva (18 de fevereiro a 30 de março de 2008) foi finalizado com uma avaliação elaborada de forma centralizada e aplicada em cada turma/série/nível de ensino de toda rede estadual em um único dia predeterminado pela SEE/SP.

Logo após esse período deu-se início a utilização dos materiais e de orientações constantes no novo currículo (documento base e Cadernos dos Professores). Porém, as formações para professores ocorreram somente nas próprias unidades escolares, com mediação dos Professores Coordenadores e apoio dos demais gestores, os quais receberam orientações e formação por intermédio dos Professores Coordenadores de Oficina Pedagógicas (PCOP) da respectiva Diretoria de Ensino (DE). Assim, esse foi um período em que nenhuma Orientação Técnica (OT; em horário de aula) foi realizada diretamente com professores, ou seja, os docentes em exercício não foram mais convocados para participar de cursos e/ou orientações técnicas descentralizadas ou centralizadas - as OT poderiam acontecer em Horário de Trabalho Pedagógico Coletivo (HTPC), mediante solicitação dos gestores. Configura-se, portanto, a implantação de uma nova proposta de currículo com a decorrente exigência de ações que se mostrassem consistentes com conteúdos e práticas didáticas preconizadas em tal documento, sendo que tal exigência, contudo, prescindia de estudo, de discussões, e, principalmente, de medidas ou de evidências mi- 
nimamente convincentes de compreensão de tais prescrições pelos professores, estimados como protagonistas da efetiva implantação da nova proposta.

De modo recorrente foi possível constatar desencontros entre, de um lado, o empenho na promoção de iniciativas que pudessem ampliar o contato dos professores com dimensões da política pública de implementação do novo currículo e da avaliação em larga escala e, de outro, a produção de medidas da compreensão pelos professores de tais dimensões.

Assim, cabe mencionar que, como ação de formação continuada dos Professores da Educação Básica- nível II (PEB II) da rede estadual de ensino de São Paulo, a SEE/SP promoveu o curso A Rede Aprende com a Rede (RAR2008) cujo objetivo era possibilitar aos professores aprofundamento dos conceitos e teorias que norteiam as Propostas Curriculares de cada disciplina, bem como as metodologias indicadas nos materiais de apoio aos professores.

Embora essa ação tenha previsto a certificação dos docentes e o atendimento de todas as escolas, a participação foi restrita a um único docente de cada segmento de ensino por escola, com exceção daquelas que apresentaram o Índice de Desenvolvimento da Educação do Estado de São Paulo (IDESP) de 2007 abaixo da média estadual $\left(3,23\right.$ para o $5^{\circ}$. ano $/ 4^{\text {a }}$. série; 2,54 para o $9^{\circ}$. ano $/ 8^{\mathrm{a}}$. série e 1,41 para o $3^{\circ}$. ano do Ensino Médio; ver www.idesp.edunet.sp.gov.br; Soares, 2009). As turmas foram compostas por um número diferente de professores, conforme a quantidade de escolas sob a jurisdição de cada uma das 91 Diretorias de Ensino do Estado de São Paulo.

A pesquisa bibliográfica e documental não registra fonte que informe ou demonstre o desempenho dos professores participantes do RAR2008 em relação à compreensão, a aceitação e legitimação das diretrizes da nova Proposta Curricular. Essa dificuldade para encontrar um documento dessa natureza ilustra que a preocupação foi grande no sentido de divulgar a proposta entre os professores, mas não houve esforços proporcionais para: (a) garantir aos docentes condições de responder às exigências da propos- ta e, principalmente, de obter posicionamentos contingentes às dúvidas e às dificuldades sobre tais diretrizes; (b) obter dados sobre o entendimento, a interpretação dos professores sobre os conceitos envolvidos em tais diretrizes. Análises dos documentos que informam sobre tais ações da SEE/SP (2008b, 2009, 2010) sugerem que as autoridades estimavam uma incorporação imediata de tais conceitos pelos professores em nome da inovação do contexto educacional paulista, sendo a mencionada incorporação possivelmente considerada como consequência direta da mera exposição dos professores a um curso composto por um conjunto de passos e de etapas definidas à revelia dos efeitos das interações dos professores com os passos e etapas.

Dentre as demais atividades de formação profissional vinculadas com a nova proposta curricular cumpre mencionar que, em 2009, a Coordenadoria de Estudos e Normas Pedagógicas (CENP) e a Escola de Formação e Aperfeiçoamento de Professores (EFAP) iniciaram nova edição do curso A Rede Aprende com a Rede (RAR2009). Foram disponibilizados três cursos:

- A Rede Aprende com a Rede - PEB II, para professores;

- A Rede Aprende com a Rede - Mediação, para PCOP de currículo;

- A Rede Aprende com a Rede - Educação a Distância: para PCOP de Tecnologia.

Quanto aos materiais textuais, cumpre destacar que a documentação possivelmente mais relevante é constituída pelos Cadernos do Professor e Cadernos do Aluno.

No Caderno do Professor-Matemática, o tema principal de cada bimestre foi dividido em oito unidades, correspondendo à aproximadamente oito semanas do bimestre. O Caderno expõe orientações iniciais, sendo possível ao professor "redimensionar" os subtemas de acordo com outros condicionantes (SEE/SP, 2008d).

Para a abordagem das oito unidades, em cada bimestre são apresentadas quatro Situações de Aprendizagem que deveriam constituir quatro centros de interesse a serem desenvolvidos com os alunos. Algumas dessas Situações de Aprendizagem são formas não 
usuais de tratamento de temas clássicos porque neste currículo há, segundo seus autores, a intenção de propiciar "visões inovadoras" para conteúdos programáticos já conhecidos. No entanto, mesmo considerando que caberá ao professor a decisão de quais centros de interesse mapear e conduzir o processo de ensino e aprendizagem, a presença de tais Situações de Aprendizagem no material de apoio denominado Caderno do Aluno, poderá ser um motivo de tensão em sala de aula. Neste caso, estima-se necessário o planejamento de condições e de atividades que possam garantir uma efetiva, consistente e coerente interpretação, pelo docente, das diretrizes propostas.

Analisando os Cadernos do Professor de Matemática, organizados por série/ano e por bimestre, é possível constatar que estão previstos conteúdos, habilidades e competências organizados por Situações de Aprendizagem e acompanhados de orientações para a gestão da sala de aula, para a avaliação e a recuperação, bem como de sugestões de métodos e estratégias de trabalho (atividades) nas aulas: experimentações, projetos coletivos, atividades extraclasse e estudos interdisciplinares.

$\mathrm{Da}$ forma como estão organizados, os Cadernos expressam uma pretensão de fornecer ao professor textos orientando-o sobre como proceder para desenvolver competências e habilidades e garantir, com isso, um desempenho satisfatório dos alunos.

Logo nas palavras inicias, nas "cartas de apresentação" dos cadernos, há afirmações a respeito de as orientações contidas incorporarem as sugestões e ajustes provenientes dos professores, advindas da experiência e da implantação da nova proposta em sala de aula desde o ano de 2008. Há também afirmações sobre a responsabilidade do trabalho do professor no alcance das metas da proposta curricular. Ressaltam, ainda, que o Caderno do Professor foi elaborado por especialistas na área de Educação, que organizaram o conteúdo por disciplina, oferecendo orientações/diretrizes didático-pedagógicas para o desenvolvimento das Situações de Aprendizagem propostas e que cabe ao professor aproveitá-las e implementá-las. Ao final, o texto explicita a prontidão para o esclarecimento de dúvidas ou de dificuldades, assim como para promover ajustes ou adaptações que aumentem a eficácia do trabalho docente.

Com esses Cadernos, a SEE/SP, segundo o texto dos próprios documentos (2010), demarcou um compromisso de apoio aos professores para que a organização dos trabalhos em sala de aula fosse o mais eficiente. Há o reconhecimento da existência de classes heterogêneas e numerosas, com alunos em diferentes estágios de aprendizagem, mas os responsáveis pela implantação do Currículo do Estado de São Paulo se dizem confiantes na capacidade de os professores administrarem, no plano pedagógico, as diferenças e a partir delas estimular o crescimento coletivo e a cooperação entre eles.

As Situações de Aprendizagem dispostas nos Cadernos são apresentadas como desencadeadoras de outras situações para abordagem de mais e mais conteúdos que compõem o Currículo. Em todos os Cadernos, os conteúdos estão organizados em oito unidades que podem corresponder a oito semanas de trabalho letivo. De acordo com o número de aulas disponíveis por semana, o professor poderá explorar cada assunto com maior ou menor complexidade. Os autores declaram que respeitam a autonomia do professor ao relatar que só o professor, em sua circunstância particular, levando em consideração seu interesse e o dos alunos pelos temas apresentados, pode determinar adequadamente quanto tempo dedicar a cada uma das unidades, mas declaram desejável que o professor tente contemplar todas as oito unidades, uma vez que, juntas, compõem um panorama do conteúdo do bimestre, e, muitas vezes, uma das unidades contribui para a compreensão das outras.

Ao longo dos Cadernos são apresentadas, além de uma visão panorâmica do conteúdo do bimestre, quatro Situações de Aprendizagem que pretendem ilustrar a forma de abordagem sugerida e/ou instrumentalizar o professor para 
sua ação em sala de aula. Compõe o Caderno, ainda, algumas considerações sobre a avaliação a ser realizada, bem como o conteúdo considerado indispensável ao desenvolvimento das competências esperadas por bimestre e que serão avaliadas pelo SARESP.

Os Cadernos também corroboram com a lógica de transmitir uma infinidade conceitos, procedimentos, normas e regras ao professor, sendo que, contudo, não há evidências de esforços depreendidos para assegurar ao professor entendimento sobre esses mesmos conceitos, normas e regras.

Assim, professores que ensinam Matemática no Ciclo II do Ensino Fundamental e no Ensino Médio encontraram, dispostas em quadros, quatro situações de aprendizagem por bimestre. Para cada situação de aprendizagem (p. ex., "a reta, a inclinação e a proporcionalidade") são informados; (a) os respectivos conteúdos; (b) estratégias de ensino recomendadas; (c) competências e habilidades.

Fundamentando e complementando os $\mathrm{Ca}$ dernos do Professor e os Cadernos do Aluno, em 2009, a SEE/SP publicou as denominadas Matrizes Curriculares de Referência para a Avaliação do SARESP (2009). As Matrizes de Referência expressam o "cruzamento" de três componentes estruturais que subsidiam o Sistema de Avaliação do Rendimento Escolar do Estado de São Paulo (SARESP): os conteúdos das diferentes áreas ou disciplinas curriculares, as competências e as respectivas habilidades. As competências descritas para cada nível de ensino e de conteúdo curricular (a saber: no nível I estão as competências para observar, no nível II, as competências para executar e no nível III, as competências para compreender), bem como as habilidades a serem avaliadas, aparentemente, expressam a eficácia do processo de ensino e aprendizagem vigente nas escolas paulistas, cabendo ao professor facilitar o desenvolvimento de tais competências. É possível, então, afirmar que cabe ao professor interpretar e implementar um conceito que se apresenta como alvo de inúmeras tentativas de definição, mas que tem sido empregado nos documentos da SEE/SP como se houvesse um consenso.
O conceito de competência é sempre apresentado, colocado, ditado e, por vezes, imposto aos professores, ignorando a discussão da multiplicidade de possíveis definições. Mesmo quando surgem espaços para "discussão" do conceito de competência, essas "discussões" giram em torno do conceito apresentado e não em torno da análise dos efeitos da proposição dos mesmos sobre as ações profissionais dos professores.

Diante de tal disposição dos documentos, ao presente trabalho caberia indagar: estamos diante de condições instrucionais necessárias e suficientes para garantir a emissão de ações profissionais consistentes com as metas e objetivos preconizados por um currículo que se pretende inovador, atualizado em termos da proposição de conteúdos e em sintonia com a integração dos mesmos com condições que garantam o exercício esperado da cidadania?

Cumpre salientar que, após praticamente 16 anos, contingente à todo um denso conjunto de ações e de programas que definiram a implantação do SARESP, constata-se uma insuficiência para reverter os números que apontam desempenhos dos alunos abaixo dos índices esperados. Concentrando ênfase em Matemática, área curricular priorizada neste estudo, o cenário mostra que $57 \%$ dos alunos terminam o ensino médio com rendimento insatisfatório de acordo com o resultado do SARESP 2010 e 58\% segundo dados de 2011, sem apresentar as competências e habilidades adequadas a essa etapa de escolarização.

Certamente vários aspectos deveriam ser considerados nas discussões e interpretações de tais resultados desfavoráveis. No âmbito deste artigo foram destacadas as possíveis necessidades formativas, ou seja, repertórios profissionais que definiriam as ações docentes em correspondência com as diretrizes e as orientações do SARESP.

Mais especificamente, a linguagem dos documentos oficiais de implantação do Currículo e a incidência dos conceitos de competência e de habilidades na avaliação de desempenho em matemática na educação básica, apresentam-se como ações diretivas da SEE/SP com o propósito de orientar os professores sobre quais compe- 
tências se relacionam com o ensino de cada um dos conteúdos disciplinares.

O texto do Currículo do Estado de São Paulo apresenta estratégias de ensino e de avaliação de competências como se todos os envolvidos no processo compartilhassem de uma mesma compreensão do conceito de competência ou, de modo mais efetivo, como se todos os envolvidos dispusessem de recursos para transformar conhecimentos sobre o conceito de competência em formas de ação, a saber, em comportamentos significativos para a obtenção das metas preconizadas pelas competências para os diferentes ciclos da alfabetização matemática na Educação Básica.

De acordo com o argumento central deste trabalho, tal transformação apresenta-se como necessidade formativa crítica, urgente e imperativa, não para legitimar uma política pública atualmente vigente e passível de substituição e de superação. Mas, antes, para garantir condições de desenvolvimento profissional mais amplas, mais genéricas e flexíveis, que permitam aos professores posicionamentos mais fundamentados e mais autônomos sobre o alcance das exigências que recorrentemente lhes são impostas sob diferentes discursos e que, em última análise, modulam avaliações da qualidade da sua atuação profissional.

A próxima seção discute uma proposta de programa de investigação e de intervenção que poderia aproximar um robusto tratamento analítico comportamental de competências da necessidade formativa acima assinalada para a alfabetização matemática na Educação Básica.

\section{Análise do Comportamento e Necessidades Formativas: Delineando Programas de Investigação e de Intervenção}

A Análise do Comportamento sustenta, de modo inconteste, nas últimas décadas, um robusto acervo de contribuições para a compreensão de processos de ensino e de aprendizagem em contextos diversos (Henklain \& Carmo, 2013; Hübner \& Marinotti, 2004; Kates-McElrath, Agnew, Axelrod, \& Bloh, 2007; McComas,
Vollmer, \& Kennedy, 2009; Tourinho \& Luna, 2010) e, especialmente, no âmbito da aquisição e do desenvolvimento de repertórios matemáticos (Carmo \& Prado, 2010; Levingston, Neef, \& Cihon, 2009; Luna \& Marinotti, 2010; Neef, Nelles, Iwata, \& Page, 2003; Wood, Frank, \& Wacker, 1998).

Em tais contribuições é possível identificar uma variedade de delineamentos de investigação, de características demográficas dos participantes, de recursos materiais para coleta e tabulação de dados, bem como de proximidade com contextos aplicados de ensino e de aprendizagem.

Parece-nos, todavia, que o deslocamento de parcela de tais contribuições para a investigação de processos de aprendizagens profissionais da docência vinculados com incidências da consolidação dos sistemas de avaliação em larga em escala na Educação Básica ainda se reveste de originalidade.

Em consonância com a diversidade de contribuições da Análise do Comportamento para a Educação e de modo a fortalecer expansões em tais contribuições, o presente artigo advoga que as necessidades formativas para a atuação docente no ensino de conteúdos curriculares de Matemática na Educação Básica, caracterizadas acima por ocasião da implantação do Currículo e do SARESP, expõem um quadro propício para investigações e intervenções respaldadas em acervos de conhecimentos derivados da produção de pesquisas em Análise do Comportamento.

Assim, as necessidades formativas priorizadas no âmbito deste artigo são definidas por um tratamento do termo competências que se apresenta como obstáculo para um exercício da docência que sustente consistência com dimensões da política pública de avaliação em larga escala. No documento que expõe os indicadores (descritores) ou as expectativas de aprendizagem ao final dos diferentes ciclos da Educação Básica, a saber, as Matrizes de Referência (SEE/SP, 2009) para a elaboração dos itens que compõem a prova do SARESP, as competências foram qualificadas como cognitivas e consistem em ações e em operações mentais utilizadas pelo aluno 
para relacionar objetos, situações, fenômenos e pessoas, todos passíveis de conhecimento. As competências cognitivas traduzem o quanto as habilidades puderam aplicar-se em situações específicas sob exame. Para demarcar o que torna possível as ações, as operações e as aplicações, o documento expõe um tratamento das competências em termos de modalidades estruturais da inteligência. Enquanto modalidades estruturais, as competências se constituem "por aquilo" (SEE/SP, 2009, p. 16) que integram, que articulam ou que configuram como resposta às indagações expostas nos itens da prova (SARESP), ou seja, expressam "o que" (SEE/SP, 2009, p. 16) é necessário para compreender ou resolver um problema. De modo complementar, como modalidades, as competências representam modos, formas ou caminhos diferentes de resolução, de validação e de justificação.

Argumenta-se, no presente artigo, que o tratamento teórico-conceitual acima sintetizado para o termo competência prescindiu de condições que pudessem viabilizar a necessária intepretação, pelos professores, das correspondências entre, de um lado, as aprendizagens objetivadas ou "substantivadas" ("o que"; "por aquilo") nas Matrizes de Referência (SEE/SP, 2009) e, de outro, as medidas comportamentais expressas pelos alunos em interação com as condições de ensino e de avaliação dispostas pelos professores. Sob tais condições de um tratamento teórico-conceitual foram constituídas e configuradas as necessidades formativas salientadas pela interação dos professores com a política pública de avaliação em larga escala do desempenho dos alunos da Educação Básica.

De modo avesso às restrições e aos obstáculos vinculados com a acepção de competência exposta oficialmente (SEE/SP, 2009), advoga-se que a utilização do termo comportamento para designar ou descrever as relações que deverão ocorrer como consequência da exposição do aprendiz a determinadas condições de ensino e de avaliação fundamentará ações de investigação com o nítido propósito de redução significativa, ou mesmo de eliminação, das dificuldades de atuação profissional definidas pelas necessidades formativas ora consideradas.
Em outros termos, como condição necessária para o enfrentamento e a superação das necessidades formativas a partir de uma interpretação analítico comportamental das aprendizagens preconizadas na Matriz de Referência da SEE/SP (2009), impõe-se especificar: (a) diante de quais situações e/ou condições antecedentes é esperado, desejável e oportuno a emissão dos repertórios que definem as aprendizagens preconizadas? (b) $\mathrm{O}$ que se apresenta como necessário para a ocorrência de tais aprendizagens? (c) Com o que o aluno entra ou deve entrar em contato para emitir os comportamentos desejáveis? (d) Quais são as ações que definem as aprendizagens selecionadas? (e) Quais são os resultados, produtos e efeitos esperados da ação?

Fundamentada em área denominada por programação de ensino (Bori, 1996; Botomé, 1981; Kienen, Kubo, \& Botomé, 2013; Nale, 1998; Skinner, 1968; Todorov, 2003; Todorov \& Hanna, 2010), a literatura recente em Análise do Comportamento atesta publicações diretamente comprometidas com a transformação de conteúdos, de informações a respeito de atividades desejadas, de condições propícias para manifestação de tais atividades e da realidade com a qual o aprendiz irá interagir em objetivos de ensino, ou, mais precisamente, em comportamentos que definem relações entre classes de ações, classes de condições diante das quais as ações devem ocorrer e classes de eventos decorrentes da emissão das ações sob tais condições (Botomé \& Kubo, 2002; Cortegoso \& Coser, 2011; Kienen et al., 2013; Kubo \& Botomé, 2001, 2003; Matos, 2001).

Admite-se que, em um programa de investigação e de intervenção analítico-comportamental sobre as necessidades formativas expostas na seção anterior deste artigo, as relações entre classes de eventos que definem os comportamentos pretendidos, expostos sob a designação de competências e de habilidades nas Matrizes Curriculares de Referência do SARESP (SEE/SP, 2009), devem ser contextualizados no âmbito de uma área curricular, dos temas envolvidos da Matemática, das características de atuação dos professores e dos gestores responsáveis pelas salas de aula envolvidas ou abrangidas pelo alcance 
das mudanças acima apresentadas. Diante de tais demandas, cabe ao analista do comportamento, em trabalho colaborativo e em conjunto com professores e gestores, salientar a prioridade da especificação das relações que alunos de diferentes ciclos da Educação Básica deverão estabelecer com os conteúdos matemáticos como resultado da exposição, da interação dos mesmos com as condições didáticas (atividades, instrumentos) prescritas ou admitidas como adequadas a uma dada realidade social e institucional. Em outros termos, em complemento à especificação de temas, de conteúdos e de atividades, urge identificar e descrever os comportamentos, a saber, as relações que devem ser resultantes da exposição dos alunos às atividades.

Estima-se que a especificação das classes de resposta, pelos professores da escola, em cooperação com pesquisadores, que definem ou que correspondem com as aprendizagens preconizadas sustentarão dois efeitos imediatos e relevantes: (a) ampliar as condições de comunicação e de diálogo entre os professores sobre as aprendizagens esperadas, ou seja, os professores poderão discutir sobre estratégias de ensino e medidas de desempenho a partir de descrições (relatos) que garantam maior visibilidade às ações esperadas dos alunos como resultado da exposição dos mesmos às condições de ensino; (b) favorecer aproximações e extensões dos conhecimentos produzidos sobre o desenvolvimento de repertórios pré-correntes (Oliveira-Castro \& Campos, 2004; Simonassi, Cameschi, Vilela, Valcacer-Coelho, \& Figueiredo, 2007), em particular, em contexto de importância inconteste na Educação Matemática, a saber, na área de resolução de problemas (Levingston et al., 2009; Luna \& Marinotti, 2010; Neef et al., 2003; Wood et al., 1998).

Considera-se que repertórios pré-correntes, ou seja, respostas cuja ocorrência aumentam a probabilidade de outras respostas (as correntes) ocorrerem e produzirem consequências estimadas relevantes, se constituem em repertórios intermediários, nos objetivos parciais, ou nos caminhos que deverão ser percorridos até a consecução das classes de respostas operantes que definem as aprendizagens esperadas.

\section{Conclusões}

$\mathrm{Na}$ literatura recente da Análise do Comportamento, produções recentes concentraram ênfase no delineamento de recursos metodológicos que priorizaram a derivação ou a transformação de conhecimentos e de informações (diretrizes, orientações) sobre competências de áreas profissionais (p.ex., as Diretrizes Curriculares Nacionais da Psicologia) em relações entre eventos que deveriam especificar ações desejadas dos futuros profissionais como resultado da exposição às condições e às atividades de ensino previstas em matrizes curriculares.

Procedimentos metodológicos aplicados sobre bases documentais priorizaram a consideração das relações entre os sujeitos da ação (no caso da literatura mencionada, graduandos em Psicologia e futuros profissionais), os verbos como as classes de respostas que os sujeitos deverão emitir (as práticas profissionais) e o complemento como aspectos do contexto em relação aos quais os sujeitos da ação deverão atuar (Kienen, 2008; Kienen et al., 2013; Kubo \& Botomé, 2001, 2003; Mattana, 2004; Santos, 2006). Os procedimentos mostraram-se eficientes para a derivação ou transformação de informações em amplos conjuntos de aprendizagens ou de classes de comportamentos que, de modo simultâneo, forneceram visibilidade aos preceitos das Diretrizes, bem como indicaram restrições nos verbos e nos complementos que podem comprometer a articulação de propostas de formação profissional.

Em termos conclusivos, o tratamento dispensado pela literatura recente à demarcação das aprendizagens e das competências profissionais do futuro psicólogo a partir das Diretrizes Curriculares Nacionais admite uma profícua proposta de extensão que, em última instância, poderá demarcar relevantes e oportunas contribuições da Análise do Comportamento em processos formativos de docentes da Educação Básica no contexto das avaliações em larga escala, em especial, no SARESP.

Parece-nos que, a exemplo das Diretrizes, a documentação da SEE/SP, em especial, os Cadernos do Professor e as Matrizes de Referência, 
dispõe expectativas de aprendizagem e de níveis de competências para o desempenho dos alunos de diferentes ciclos na área curricular de Matemática.

A interpretação das correspondências entre tais expectativas e níveis de competências com as ações dos alunos em situação de ensino em sala de aula não se mostrou como resultado "natural" das interações dos professores com as ações de "formação" profissional da SEE/SP, tampouco com a documentação oficial disposta para os professores (Barros, 2014; Peralta, 2012).

As lacunas no desenvolvimento dos repertórios de ensino definidos pelo estabelecimento das interpretações de tais correspondências foram, no presente artigo, caracterizadas como necessidades formativas fomentadas e agravadas em função do modo como foi efetivada a implantação do Currículo e do SARESP.

Conjectura-se que a aplicação, pelos próprios professores, dos procedimentos de derivação das competências e de transformação de conhecimentos vinculados com as mesmas em classes de comportamentos intermediários (repertórios pré-correntes que definem caminhos, trajetórias de aprendizagem) e terminais poderia melhor qualificar a atuação profissional no ensino de repertórios estimados relevantes para a educação matemática na Educação Básica.

Assim, programas de investigação e de intervenção sobre aprendizagens profissionais da docência, ou seja, de formação de professores em serviço, deveriam priorizar a identificação e a descrição, pelos docentes, das classes de comportamentos (relações entre eventos) que definem as aprendizagens preconizadas nos documentos oficiais da SEE/SP para a área de Matemática. A partir da constatação das identificações e descrições de classes de comportamentos, aos professores caberia o planejamento e a execução de unidades de ensino de tais classes de comportamentos, bem como a avaliação da efetividade de tais unidades no estabelecimento das medidas comportamentais que definem as aprendizagens esperadas.

Em seu conjunto, poder-se-ia considerar que programas assim orientados se constituiriam em ações de investigação e de intervenção me- diadas por conhecimentos derivados da Análise do Comportamento, sobre necessidades formativas de professores da rede pública de Educação Básica, considerando-se características das trajetórias de formação dos próprios professores e os impactos das expectativas oficiais de desempenho dos alunos na atuação profissional dos mesmos.

\section{Referências}

Barros, R. C. (2104). A Educação Matemática nos anos iniciais: Análises de necessidades de formação profissional de docentes no contexto do SARESP (Dissertação de mestrado, Programa de Pós-Graduação em Educação para a Ciência, Universidade Estadual Paulista "Júlio de Mesquita Filho", Bauru, SP, Brasil). Recuperada em http://base.repositorio.unesp.br/handle/11449/110895

Bori, C. (1996). Chapters in the life of Fred S. Keller. Psicologia: Teoria e Pesquisa, 12, 189-190.

Botomé, S. (1981). Objetivos comportamentais no ensino: A contribuição da Análise Experimental do Comportamento (Tese de doutorado não-publicada, Departamento de Psicologia Experimental, Universidade de São Paulo, SP, Brasil).

Botomé, S., \& Kubo, O. (2002). Responsabilidade social dos programas de pós-graduação e formação de novos cientistas e professores de nível superior. Interação em Psicologia, 6(1), 81-109. doi:10.5380/psi.v6i1.3196

Carmo, J. S., \& Prado, P. (2010). Relações simbólicas e aprendizagem da Matemática. Santo André, SP: ESETec.

Cortegoso, A. L., \& Coser, D. S. (2011). Elaboração de programas de ensino: Manual autoinstrutivo. São Carlos, SP: Editora da Universidade Federal de São Carlos.

Henklain, M., \& Carmo, J. (2013). Contribuições da Análise do Comportamento à Educação: Um convite ao diálogo. Cadernos de Pesquisa, 43(149), 704-723. doi:10.1590/S010015742013000200016

Hübner, M. M., \& Marinotti, M. (2004). Análise do Comportamento para a Educação: Contribuições recentes. Santo André, SP: ESETec.

Kates-McElrath, K., Agnew, M., Axelrod, S., \& Bloh, C. (2007). Identification of behavioral function 
in public schools and a clarification of terms. $\mathrm{Be}$ havioral Interventions, 22, 47-56. doi:10.1002/ bin. 230

Kienen, N. (2008). Classes de comportamentos profissionais do psicólogo para intervir, por meio do ensino, sobre fenômenos e processos psicológicos, derivadas a partir das Diretrizes Curriculares, da formação desse profissional e de um procedimento de decomposição de comportamentos complexos (Tese de doutorado, Programa de Pós-Graduação em Psicologia, Centro de Filosofia e Ciências Humanas, Universidade Federal de Santa Catarina, Florianópolis, SC, Brasil). Recuperada em http://www.dominiopublico.gov.br/pesquisa/DetalheObraForm. do?select_action $=\&$ co_obra $=141318$

Kienen, N., Kubo, O., \& Botomé, S. (2013). Ensino programado e programação de condições para o desenvolvimento de comportamentos: Alguns aspectos no desenvolvimento de um campo de atuação do psicólogo. Acta Comportamentalia, 21(4), 481-494.

Kubo, O., \& Botomé, S. (2001). Ensino-aprendizagem: Uma interação entre dois processos comportamentais. Interação em Psicologia, 5(1), 123-132.

Kubo, O., \& Botomé, S. (2003). A transformação do conhecimento em comportamentos profissionais na formação do psicólogo: As possibilidades nas Diretrizes Curriculares. In M. Z. S. Brandão, F. C. S. Conte, F. S. Brandão, Y. K. Ingberman, C. B. de Moura, V. M. da Silva, \& S. M. Oliane (Eds.), Sobre comportamento e cognição: Vol. 11 (pp. 483-496). Santo André, SP: ESETec.

Levingston, H., Neef, N., \& Cihon, T. (2009). The effects of teaching precurrent behaviors on children's solution of multiplication and division word problems. Journal of Applied Analysis of Behavior, 42(2), 361-367. doi:10.1901/ jaba.2009.42-361

Luna, S. V., \& Marinotti, M. (2010). Ensino da resolução de problemas: Questões conceituais e metodológicas. In E. Z. Tourinho \& S. V. Luna (Eds.), Análise do Comportamento: Investigações históricas, conceituais e aplicadas (pp. 193-217). São Paulo, SP: Roca.

Matos, M. A. (2001). Contingências no aprender e no ensinar. In E. S. Alencar (Ed.), Novas contribuições da Psicologia aos processos de ensino e aprendizagem (pp. 142-165). São Paulo, SP: Cortez.
Mattana, P. E. (2004). Comportamentos profissionais do terapeuta comportamental como objetivos para a sua formação (Dissertação de mestrado, Programa de Pós-Graduação em Psicologia, Centro de Filosofia e Ciências Humanas, Universidade Federal de Santa Catarina, Florianópolis, SC, Brasil). Recuperada em http://repositorio.ufsc.br/handle/123456789/88195

McComas, J., Vollmer, T., \& Kennedy, C. (2009). Descriptive analysis: Quantification and examination of behavior-environment interactions. Journal of Applied Analysis of Behavior, 42(2), 411-412.

Nale, N. (1998). Programação de Ensino no Brasil: O papel de Carolina Bori. Psicologia USP, 9(1). doi:10.1590/S0103-65641998000100058. Recuperado em 14 de janeiro de 2012, em http://www.scielo.br/scielo.php?pid=S0103$-65641998000100058 \&$ script $=$ sci_arttext

Neef, N., Nelles, D., Iwata, B., \& Page, T. (2003). Analysis of precurrent skills in solving mathematics story problems. Journal of Applied Behavior Analysis, 36(1), 21-33. doi:10.1901/ jaba.2003.36-21

Oliveira-Castro, J., \& Campos, A. P. (2004). Comportamento precorrente auxiliar: Efeitos do número de dimensões discriminativas de tarefa. Psicologia: Teoria e Pesquisa, 20(2), 191-199.

Peralta, D. A. (2012). Políticas públicas de implantação curricular e de avaliação em larga escala: Necessidades formativas de professores de Matemática e contribuições da Teoria da Ação Comunicativa (Tese de doutorado, Programa de Pós-Graduação em Educação para a Ciência, Universidade Estadual Paulista "Júlio de Mesquita Filho", Bauru, SP, Brasil). Recuperada em http://www2.fc.unesp.br/BibliotecaVirtual/DetalhaDocumentoAction.do?idDocumento $=484$

Santos, G. C. V. (2006). Características das competências e dos comportamentos profissionais propostos nas diretrizes curriculares como delimitação do campo de atuação do psicólogo (Dissertação de mestrado, Programa de Pós-Graduação em Psicologia, Centro de Filosofia e Ciências Humanas, Universidade Federal de Santa Catarina, Florianópolis, SC, Brasil). Recuperada em http://repositorio.ufsc.br/handle/123456789/89429

Secretaria da Educação do Estado de São Paulo. (2008a). Proposta Curricular do Estado de São 
Paulo/SEE-SP. São Paulo, SP: Fundação para o Desenvolvimento da Educação.

Secretaria da Educação do Estado de São Paulo. (2008b). Proposta Curricular do Estado de São Paulo: Matemática. Ensino Fundamental: Ciclo II e Ensino Médio. São Paulo, SP: Autor.

Secretaria da Educação do Estado de São Paulo. (2008c). Orientações Curriculares do Estado de São Paulo: Língua Portuguesa e Matemática Ciclo I. São Paulo, SP: Fundação para o Desenvolvimento da Educação.

Secretaria da Educação do Estado de São Paulo. (2008d). Caderno do Professor: Matemática. São Paulo, SP: Autor.

Secretaria da Educação do Estado de São Paulo. (2009). Matrizes Curriculares de Referência do Sistema de Avaliação de Rendimento Escolar do São Paulo (M. I. Fini, Coord.). São Paulo, SP: Autor.

Secretaria da Educação do Estado de São Paulo. (2010). Currículo do Estado de São Paulo: Matemática e suas tecnologias (M. I. Fini \& N. J. Machado, Coords.). São Paulo, SP: Autor.

Simonassi, L., Cameschi, C., Vilela, J., Valcacer-Coelho, A., \& Figueiredo, V. (2007). Inferências sobre classes de operantes precorrentes verbais privados. Revista Brasileira de Análise do Comportamento, 3(1), 97-113.

Skinner, B. F. (1968). The technology of teaching. New York: Appleton-Century-Crofts.
Soares, J. F. (2009). Índice de Desenvolvimento da Educação de São Paulo/IDESP: Bases metodológicas. São Paulo em Perspectiva, 23(1), 29-41.

Todorov, J. (2003). O legado de FSK. In M. Z. S. Brandão F. C. S. Conte, F. S. Brandão, Y. K. Ingberman, C. B. de Moura, V. M. da Silva, \& S. M. Oliane (Eds.), Sobre comportamento e cognição: Vol. 11 (pp. 15-20). Santo André, SP: ESETec.

Todorov, J. C., \& Hanna, E. (2010). Análise do Comportamento no Brasil. Psicologia: Teoria e Pesquisa, 26, 143-153. doi:10.1590/S010237722010000500013

Tourinho, E., \& Luna, S. (2010). Análise do Comportamento: Investigações históricas, conceituais e aplicadas. São Paulo, SP: Roca.

Wood, D., Frank, A., \& Wacker, D. (1998). Teaching multiplication facts to students with learning disabilities. Journal of Applied Analysis of Behavior, 31(3), 323-338. doi:10.1901/jaba.1998.31323

Recebido: 16/12/2012

$1^{a}$ revisão: 12/04/2014 Aceite final: 15/07/2014 